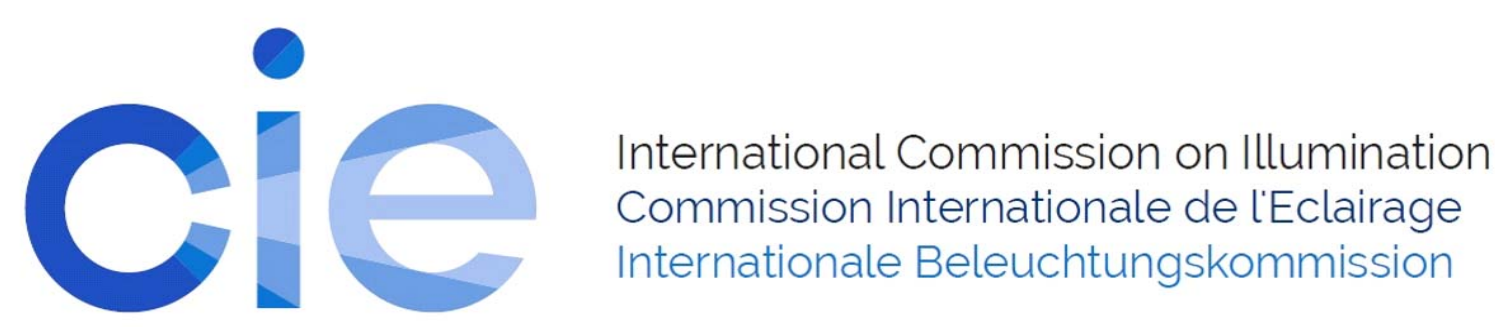

PP24

\title{
IMPACT OF THE SPECTRUM OF LIGHT ON VISIBILITY IN ROAD TUNNELS
}

\author{
Dorian TALON et al.
}

DOI 10.25039/x46.2019.PP24

from

CIE x046:2019

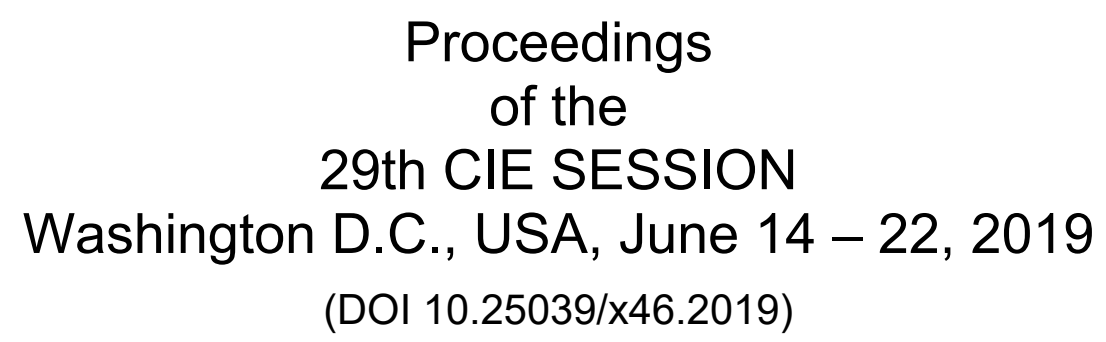

The paper has been presented at the 29th CIE Session, Washington D.C., USA, June 14-22, 2019. It has not been peer-reviewed by CIE.

(C) CIE 2019

All rights reserved. Unless otherwise specified, no part of this publication may be reproduced or utilized in any form or by any means, electronic or mechanical, including photocopying and microfilm, without permission in writing from CIE Central Bureau at the address below. Any mention of organizations or products does not imply endorsement by the CIE.

This paper is made available open access for individual use. However, in all other cases all rights are reserved unless explicit permission is sought from and given by the CIE.

CIE Central Bureau

Babenbergerstrasse 9

A-1010 Vienna

Austria

Tel.: +4317143187

e-mail: ciecb@cie.co.at

www.cie.co.at 


\title{
IMPACT OF THE SPECTRUM OF LIGHT ON VISIBILITY IN ROAD TUNNELS
}

\author{
Talon, D. ${ }^{1}$, Dumortier, D. ${ }^{1}$, Jost, S. ${ }^{1}$, Besson, S. ${ }^{2}$ \\ 1 University of Lyon, ENTPE, Lyon, FRANCE, ${ }^{2}$ CETU, Bron, FRANCE \\ dorian.talon@entpe.fr
}

DOI 10.25039/x46.2019.PP24

\begin{abstract}
Our objective is to investigate the effect of the spectral content of light sources on visibility in road tunnels. This paper describes the psychophysical experiment that we developed for this investigation. We have built a 1:20 scale model of a tunnel equipped with 2 rows of 12 chips on board (COB) acting as luminaires. Each $\mathrm{COB}$ contains 7 different types of LED which are individually controlled to produce various spectral power distributions (SPD). We will focus on three SPD: one representative of high pressure sodium lamps (HPS) and two others representative of white LEDs at Correlated Colour Temperature (CCT) of $3000 \mathrm{~K}$ and $5000 \mathrm{~K}$ respectively. In order to determine whether or not melanopsin plays a role in visibility, three other spectra will be tested: each being metameric (same CCT and CRI) of one of the first three, while providing up two twice as much energy around $490 \mathrm{~nm}$ (the peak of melanopsin sensitivity). About 40 observers will compare the visibility of an on-axis target under the six spectra using a pairwise comparison procedure.
\end{abstract}

Keywords: Tunnel, Visibility, LED, Spectral Power Distribution, Melanopsin, Metameric spectra.

\section{Introduction}

\subsection{LED sources}

The light sources which have been traditionally used in road tunnels so far are high pressure sodium lamps (HPS) and fluorescent tubes. The latter are almost exclusively installed in the interior zone as their slender shape is well adapted to provide good visual guidance and longitudinal uniformity. In contrast, the fluorescent tubes are not used in the threshold zone, their size does not allow to find a positioning which provides sufficient luminance levels. The HPS sources can be installed in both the threshold and the interior zones, but they offer a poor colour rendering. Moreover, they present a low Scotopic/Photopic (S/P) ratio and are consequently not very effective in the mesopic domain.

Another type of light sources is increasingly used in road lighting and, by extension, in tunnels: the LEDs. The recent technological advances have considerably improved their luminous efficiencies and their output fluxes, in such a way that they can be used in replacement of HPS sources (in the threshold and interior zones). Moreover, the LED technology offers a wide range of spectra, quite different from the one of HPS sources. Colour LEDs can be mixed to produce almost any spectrum specifically designed to address the drivers' photoreceptors. Their Colour Rendering Index (CRI) will depend on the spectrum and can be much higher than the one of HPS lamps.

These intrinsic differences between traditional light sources and LEDs question the actual methods of lighting in road tunnels. The wide range of spectra now available encourage the scientists to consider more precisely the role of each photoreceptor (visual and non-visual), in order to choose the most efficient spectral power distribution (SPD) offering a compromise between comfort, visibility and energy savings.

\subsection{Previous work on the influence of SPD on visibility in road tunnels}

The actual lighting recommendations for road tunnels impose levels of luminance based on the photopic luminosity function, even in the interior zone where the light levels are very low (between $1 \mathrm{~cd} \cdot \mathrm{m}^{-2}$ and $10 \mathrm{~cd} \cdot \mathrm{m}^{-2}$ ) (CIE 2004, CETU 2000, CEN 2006). However, several studies showed that, for these kinds of light levels, the photopic function is not necessarily well adapted 
to describe the visual feeling of drivers (Yang et al. 2011). Consequently, these studies brought out a transition domain between scotopic and photopic visions in which both cones and rods are active: the mesopic vision. The upper and lower limits of this domain vary from one model to another (Rea et al. 2004, Eloholma and Halonen 2005), but the intermediate model developed by the CIE indicates lower and upper limits of $0,005 \mathrm{~cd} \cdot \mathrm{m}^{-2}$ and $5 \mathrm{~cd} \cdot \mathrm{m}^{-2}$ respectively $(\mathrm{CIE}$ 2010). We notice that for these limits, many tunnels' interior zones are affected, meaning that the luminance levels measured for these zones don't fairly represent the perception of drivers. Indeed, the rods are not taken into account in photopic vision, whereas they likely play a role in the process of vision under low light levels. Finally, the luminance levels quoted above could be overestimated if the S/P ratio of the light source is less than one, and it could be underestimated otherwise.

Many studies investigated the impact of SPD on visibility considering these mesopic conditions. The first of them were concerned with road lighting in general, then some experimentations specific to tunnels were conducted. The mesopic vision is known to impact mainly the peripheral visual field, as the rods are mostly located in the peripheral retina (Curcio et al. 1990). Consequently, many studies tested the ability of subjects to detect a target appearing briefly in their peripheral visual field. Some of them focused on classic road lighting (Bullough and Rea 2000), while others were designed specifically to address the tunnel issue (He et al. 2017). The results obtained for these two categories were consistent and showed that the visual performances of observers increased with the S/P ratio of the light sources. Some experiments investigated also the impact of SPD on central vision for low light levels (Górczewska et al. 2013). The statement about the role of S/P ratio enunciated for peripheral vision was also true for central vision: the visual performances of the observers were better under LED lighting than under HPS lighting and the lower the levels of luminance are, the greater the difference of visual performance between HPS and LED will be.

All these studies showed that for the same levels of photopic luminance, different light sources could produce different visual perceptions and performances. The S/P ratio allows to get a first estimation of the efficiency of a light source in the mesopic domain, but the total SPD is more accurate as it can be compared directly with the eye sensitivity functions.

The mesopic conditions modify the values of luminance at low light levels because they take into account the potential role of the rods in the vision process. They are more accurate since they consider the vision process in a more comprehensive manner, so to speak. With this in mind, it seems logical to examine the potential existence of other photoreceptors which could also participate to the visual performances of drivers. For example, the intrinsically photosensitive Retinal Ganglion Cells (ipRGCs), which contain a light sensitive molecule called melanopsin, are well known for their non-visual effects (notably for their role in the circadian cycles), while their impact in the conscious vision is less clear. Nevertheless, recent studies aimed at filling these gaps and highlighted the role of ipRGCs in pupillary light reflex and in brightness estimation.

The first experiments showed that the steady-state pupilloconstriction was mainly due to the excitation of ipRGCs (Gamlin et al. 2007). Simultaneously, some tests were run with blind people and demonstrated that the latter were able to detect a monochromatic stimulus at 481 $\mathrm{nm}$ : it was one of the first evidence that these cells play a direct role in the vision process (Zaidi et al. 2007). Later, the study of the impact of melanopsin on the human pupillary light reflex was developed, confirming that the cones participate in rapid responses, while the ipRGCs contribute to modulate sustainably the size of the pupil (Mc Dougal and Gamlin 2010, Brown et al. 2012). Recently, the experiments have become predominantly interested in brightness perception. Two main methods are used to this end: the silent substitution (Estevez and Spekreijse 1982) and the metameric spectra. The first one aims to neutralize the responses of all the other photoreceptors in order to test the ones related to melanopsin. The second one consists in the comparison of two stimuli which present the same Correlated Colour Temperature (CCT) and CRI, but different SPD (which means different melanopic excitations). The results obtained with these two different methods were the following:

- The increase of melanopic excitation is linked with a higher perceived luminosity; 
- The ipRGCs impact mainly the peripheral visual field (Esquiva et al. 2017, Zele et al. 2018b);

- The brightness estimation is the result of an interaction between signals emitted by the cones and the ones emitted by the ipRGCs (Zele et al. 2018a).

It should be noted that none of the experiments quoted above investigated the impact of ipRGCs on the driving task. Nevertheless, there is evidence that the melanopsin impacts directly the vision process. Therefore, it could play a role in the visual performance of drivers.

Figure 1 shows the spectral sensitivities of every type of photoreceptor.

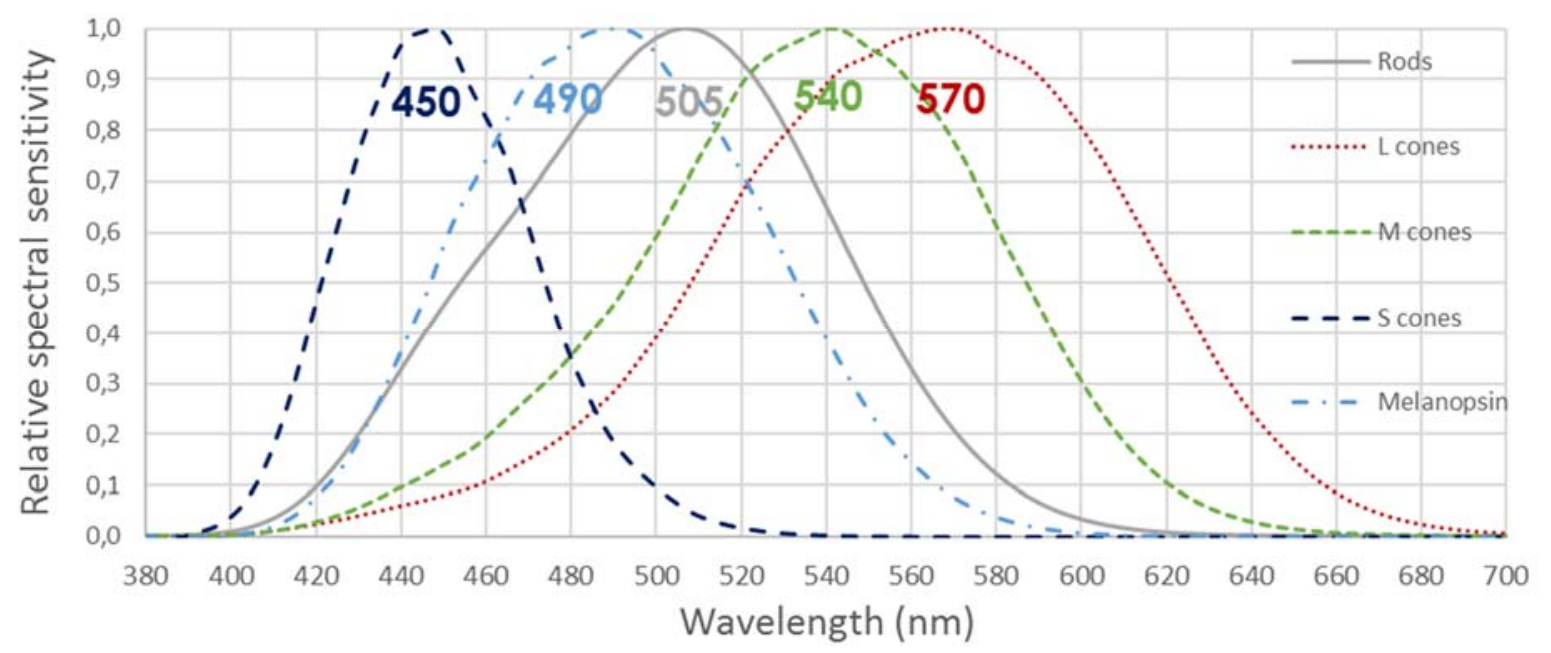

Figure 1 - Spectral sensitivities of visual and non-visual human photoreceptors

\subsection{Goals and hypothesis}

As mentioned above, several studies showed that SPD has an effect on visibility in road tunnels in mesopic conditions. This effect is known to happen mainly in peripheral vision. As regards the ipRGCs, there is evidence that they impact directly the vision process. This impact seems also to be felt predominantly in peripheral vision.

Very few papers worked on the impact of SPD in central vision for mesopic conditions or on the role of ipRGCs at low light levels. So, our objectives are to fill these gaps. Our research questions are:

1. Does the change of spectrum due to the switch from HPS to LED technology impacts drivers' visibility in their central vision?

2. Does the excitation of ipRGCs impact visibility?

A psychophysical experiment in laboratory conditions was designed to investigate these questions, it is described in the following.

\section{Experimental material}

\subsection{Scale model of tunnel}

A 1:20 scale model of a tunnel (unidirectional tube with two ways) was built for this experiment. We relied on a scale model instead of simulations on screen for two reasons: (1) to get visibility conditions which are close to reality (better immersion) and (2) to insure that observers would be exposed to real SPDs (difficulty with screens). The dimensions of the tunnel and the conditions of target observation are given in Table 1. 
Table 1 - Dimensions of the 1:20 scale model and equivalence with a real situation.

\begin{tabular}{|l|c|c|}
\hline & $\begin{array}{c}\text { Measure in the scale } \\
\text { model }\end{array}$ & $\begin{array}{c}\text { Measure in the reality } \\
\text { (20x scale model) }\end{array}$ \\
\hline Width of the tunnel & $0,5 \mathrm{~m}$ & $10 \mathrm{~m}$ \\
\hline Height of the tunnel & $0,25 \mathrm{~m}$ & $5 \mathrm{~m}$ \\
\hline Length of the tunnel & $5 \mathrm{~m}$ & $100 \mathrm{~m}$ \\
\hline $\begin{array}{l}\text { Longitudinal } \\
\text { distance between } \\
\text { two luminaires } \\
\text { (middle to middle) }\end{array}$ & $0,4 \mathrm{~m}$ & $8 \mathrm{~m}$ \\
\hline $\begin{array}{l}\text { Transversal distance } \\
\text { between two } \\
\text { luminaires (middle to } \\
\text { middle) }\end{array}$ & $0,215 \mathrm{~m}$ & $4,3 \mathrm{~m}$ \\
\hline Target size & $0,01 \mathrm{~m}$ & $0,2 \mathrm{~m}$ \\
\hline $\begin{array}{l}\text { Observation } \\
\text { distance }\end{array}$ & $4 \mathrm{~m}$ & $80 \mathrm{~m}$ \\
\hline $\begin{array}{l}\text { Eye level above the } \\
\text { road }\end{array}$ & $0,075 \mathrm{~m}$ & $1,5 \mathrm{~m}$ \\
\hline
\end{tabular}

The scale model was built using an aluminium structure supporting painted wood panels which act as road, walls and ceiling. We used greys N5 and N7 Munsell paints for the target and the lower half of the walls respectively. The ceiling and upper half of the walls were painted with a mat black paint from Tollens. The road was painted with a mix of the same mat black paint and a mat white paint from Tollens. The spectral reflection factors have been calculated for each surface using a JETI Specbos 1211-UV spectroradiometer and a BN R98 SQ reflection standard from Gigahertz-Optik. The surfaces are supposed to be Lambertian. The spectral reflection factors are given in Figure 2. $\rho_{\text {ceiling }}$ is the spectral reflection factor of the upper half of the walls and of the ceiling, $\rho_{\text {road }}$ refers to the road, $\rho_{\text {target }}$ to the target and $\rho_{\text {walls }}$ to the lower half of the walls.

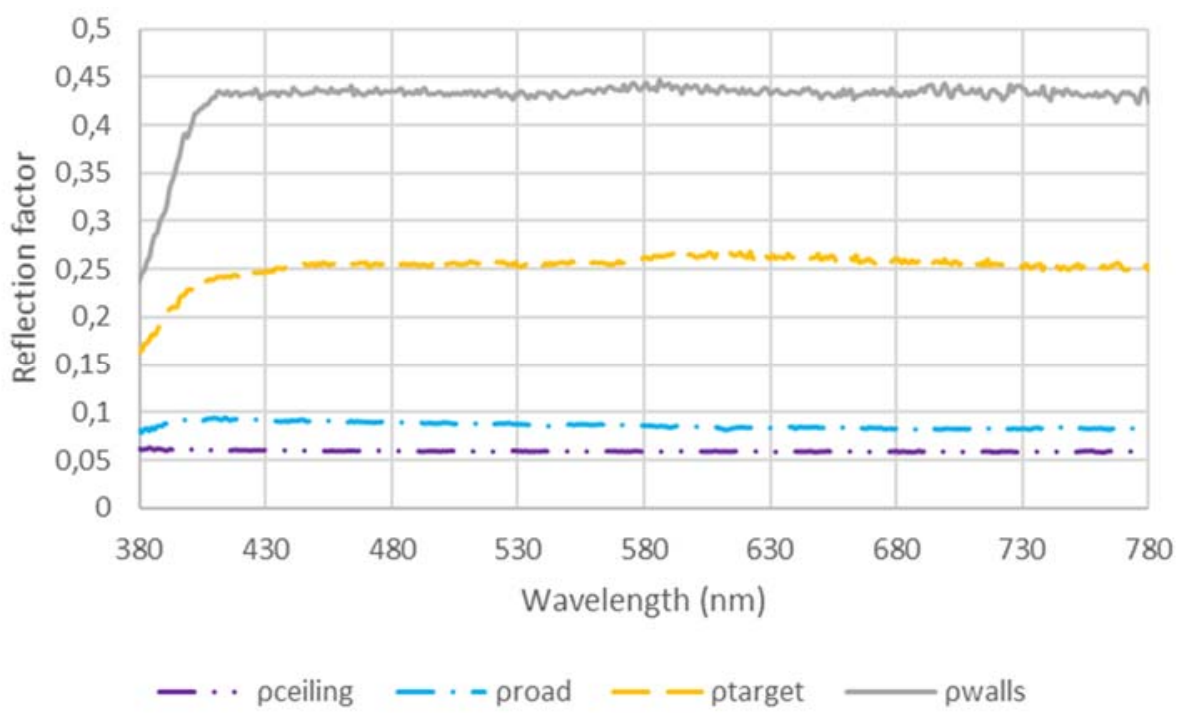

Figure 2 - Spectral reflection factors in the scale-model

The observers will seat on a chair and look directly at the $1 \mathrm{~cm}$ by $1 \mathrm{~cm}$ square target (on axis target), $4 \mathrm{~m}$ ahead. The middle of their eyes will be $7,5 \mathrm{~cm}$ above the road, this value is maintained constant thanks to a chinrest. The model is illuminated by 2 rows of 12 LED chips 
on board (COB) LZ7 04M100 from the LED Engin company acting as luminaires. Figure 3 shows the experimental set-up.

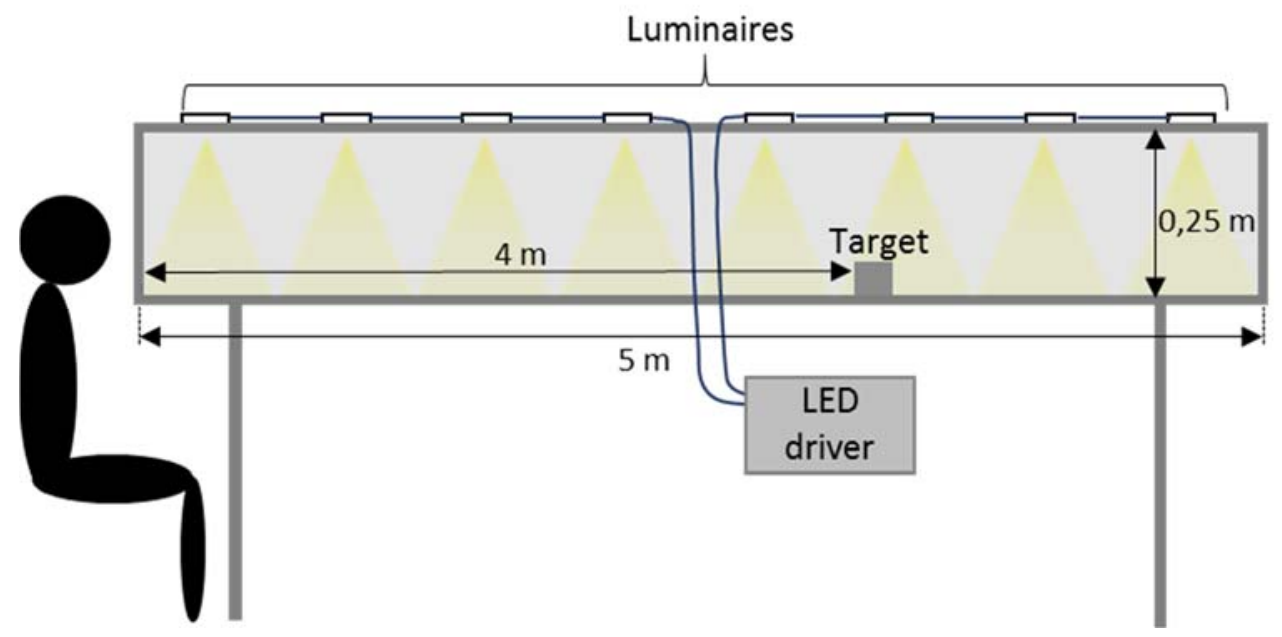

Figure 3 - Experimental 1:20 scale model of a tunnel

\subsection{Light stimuli}

The LZ7 04M100 COB includes 7 different chips (red, green, blue, $6500 \mathrm{~K}$ white, amber, cyan and violet) which can be individually controlled to create a wide range of spectra. Practically, the 24 LZ7 are divided in two different circuits for each chip. In each circuit, the 12 chips are in series. The two different circuits are controlled by the same driver (one driver for one chip type). Finally, each driver is addressed by a DMX channel via a LabVIEW interface, thus the output intensity of each type of chip can be controlled precisely to get the desired spectrum. To summarise the electrical installation, there are 14 series circuits controlled by seven LED drivers POWERDRIVE 1060A from the eldoLED company. Figure 4 shows the spectral irradiance of the seven chip types of the LZ7 04M100 COB, measured at full power on the road just before the target.
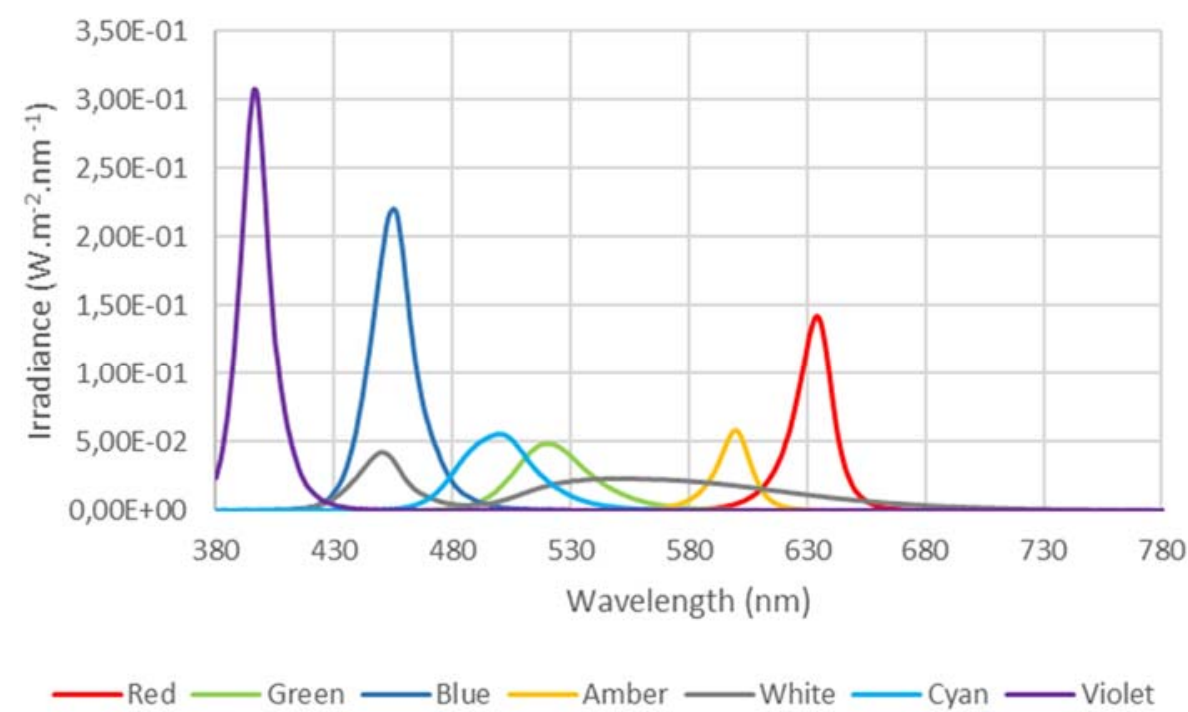

\section{Figure 4 - Spectral irradiance measured on the road before the target} when the coloured chips are at full power

These seven chip types are used to produce 6 different SPDs in order to answer the research questions mentioned above. Three of the SPDs are typical of HPS, $3000 \mathrm{~K}$ white LED and $5000 \mathrm{~K}$ white LEDs. They are designed to answer the problematic of the change from HPS to LED. Then, they are three other SPDs which are metameric equivalents of the first three. They 
are designed to investigate the impact of melanopsin on visibility at low light levels. These SPDs were created via an optimisation program run under Matlab. The latter finds the metameric spectrum which has approximately the same tristimulus values and the same CRI as a reference spectrum (low melanopsin excitation spectrum), while maximizing (up to twice as much) its melanopic excitation potential. The characteristics of the 6 different SPDs are presented in Table 2 and 3. The data given for the two HPS spectra were measured on the road just before the target with the spectroradiometer. Two measures were made: one for spectral irradiance and one for spectral radiance. The measured luminance data correspond to the radiance measure, while the calculated luminance data were obtained by using the Lambert's law with the values collected during the spectral irradiance measure. The data given for the four remaining spectra are theoretical values obtained with the optimization program. There were not measured because of time limitations.

Table 2 - CCT, reference indexes $R_{f}$ (TM 30-18) and CIE tristimulus values of the 6 spectra

\begin{tabular}{|l|c|c|c|c|c|}
\hline & $\mathbf{C C T}(\mathbf{K})$ & $\boldsymbol{R}_{\boldsymbol{f}}$ & $\mathbf{X}$ & $\mathbf{Y}$ & $\mathbf{Z}$ \\
\hline $\begin{array}{l}\mathbf{5} \text { 000 K } \\
\text { low mela }\end{array}$ & 4889 & 70 & 146,3 & 148,36 & 125,5 \\
\hline $\begin{array}{l}\mathbf{5} \mathbf{0 0 0} \mathbf{K} \\
\text { high mela }\end{array}$ & 5138 & 70 & 144,3 & 150,4 & 127,4 \\
\hline $\begin{array}{l}\mathbf{3} \mathbf{0 0 0} \text { K } \\
\text { low mela }\end{array}$ & 2832 & 70 & 164,3 & 149,4 & 51,6 \\
\hline $\begin{array}{l}\mathbf{3} \text { 000 K } \\
\text { high mela }\end{array}$ & 2981 & 70 & 162,3 & 151,4 & 53,6 \\
\hline $\begin{array}{l}\text { HPS low } \\
\text { mela }\end{array}$ & 2045 & 25 & 180 & 147,2 & 3,6 \\
\hline $\begin{array}{l}\text { HPS high } \\
\text { mela }\end{array}$ & 2208 & 21 & 182,4 & 153,2 & 16 \\
\hline
\end{tabular}

Table 3 - Illuminance and luminance values measured and/or calculated for the 6 spectra

\begin{tabular}{|c|c|c|c|c|c|c|}
\hline & \begin{tabular}{|c|} 
Photopic \\
illuminance \\
(Ix)
\end{tabular} & $\begin{array}{l}\text { Scotopic } \\
\text { illuminance } \\
\text { (IX) }\end{array}$ & $\begin{array}{l}\text { Melanopic } \\
\text { illuminance } \\
(\text { (Ix) }\end{array}$ & $\begin{array}{l}S / P \\
\text { ratio }\end{array}$ & $\begin{array}{c}\text { Measured } \\
\text { luminance } \\
\left(\mathbf{c d} \cdot \mathbf{m}^{-2}\right)\end{array}$ & $\begin{array}{c}\text { Calculated } \\
\text { luminance } \\
\left(\mathrm{cd} \cdot \mathrm{m}^{-2}\right)\end{array}$ \\
\hline $\begin{array}{l}5000 \mathrm{~K} \\
\text { low } \\
\text { mela }\end{array}$ & 148,4 & 267,7 & 89,1 & 1,8 & $X$ & 4,08 \\
\hline $\begin{array}{l}5000 \mathrm{~K} \\
\text { high } \\
\text { mela }\end{array}$ & 150,4 & 406,9 & 153,8 & 2,7 & $x$ & 4,15 \\
\hline $\begin{array}{l}3000 \mathrm{~K} \\
\text { low } \\
\text { mela }\end{array}$ & 149,4 & 189,3 & 59,6 & 1,3 & $x$ & 4,09 \\
\hline $\begin{array}{l}3000 \mathrm{~K} \\
\text { high } \\
\text { mela }\end{array}$ & 151,4 & 271,2 & 92,9 & 1,8 & $x$ & 4,16 \\
\hline $\begin{array}{l}\text { HPS low } \\
\text { mela }\end{array}$ & 147,3 & 90,2 & 21,4 & 0,6 & 4,29 & 4,01 \\
\hline $\begin{array}{l}\text { HPS } \\
\text { high } \\
\text { mela }\end{array}$ & 153,2 & 170,9 & 55,7 & 1,1 & 4,46 & 4,19 \\
\hline
\end{tabular}


Figure 5 shows the spectral irradiance corresponding to the 6 different spectra used in the experiment. The measure was taken on the road just before the target.

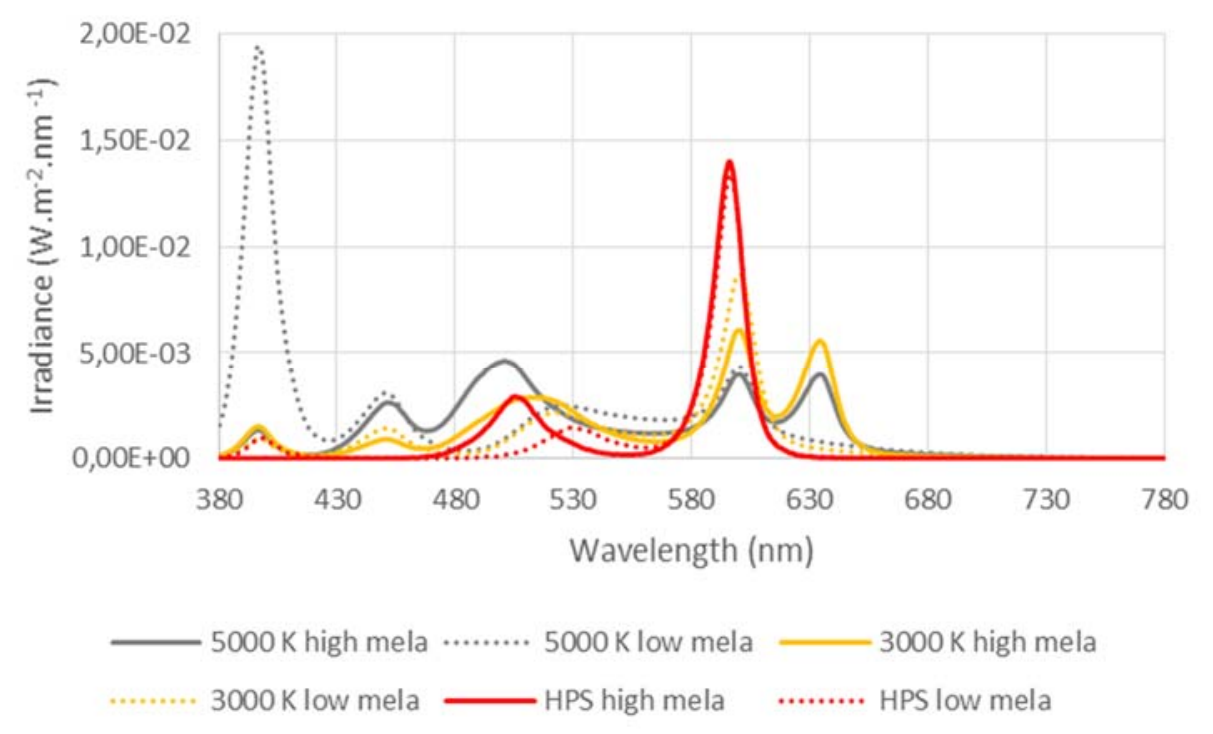

Figure 5 - Theoretical spectral irradiance of the 6 spectra used in the experiment

\section{Method}

\subsection{Experimental procedure}

A pairwise comparison method will be used for this experiment. Practically, each spectrum will be compared with all the others on the basis of target visibility. In other words, each observer will see 36 pairs of stimuli, which means all the different possible combinations of pairs for the 6 spectra (including twice the same stimulus in one pair and two pairs presenting the same stimulus in reverse order). The presentation order of the pairs will be randomized and will change for each participant. For each pair of stimuli, the observers will be asked to choose the stimulus for which the target seems to be the most visible - an equal visibility statement will not be allowed.

The pairwise comparison method was selected because it was considered as easily understandable and hardly open to interpretation. Moreover, it gives us hints to determine whether or not the experiment is biased. Indeed, the answers provided for pairs presenting twice the same spectrum will be compiled and compared to the theory which states that $50 \%$ of the observers would prefer this spectrum when presented first and $50 \%$ when presented second: if the results do not agree with this, it will imply that the experiment is biased and that the observers' choice is dependent of the presentation order of the spectra. Finally, this method can also be used to check the consistency of the answers provided by each observer. To do so, we will use the pairs comparing the same spectra in two different orders (S1 first then S1 second). We will check if, for these two pairs, the observer chose the same spectrum in both cases. If not, it will mean that the answers for these two pairs are not consistent. Thus, we will attribute a consistency rate to each observer: the answers of the observers presenting a low consistency rate (below $65 \%$ ) will not be used in processing the results, as they may skew the latter. This may be observers who didn't understand the instructions or who answered randomly.

The results are not produced yet. In practice, a score of visibility will be attributed to each spectrum. This score will be calculated as follows:

- It will be incremented by 1 each time the spectrum considered will be preferred to another in a pair;

- It will be decremented by 1 each time another spectrum will be preferred to the spectrum considered in a pair. 
The pairs presenting twice the same stimulus will not be taken into account for the calculation of the visibility score.

\subsection{Experimental protocol}

Before the beginning of the pairwise comparison, the observers will have a quick description of the experiment. They will take a visual acuity test and some general information about them will be documented (sex, age, visual anomalies...). Then they will sit with legs straight in front of the tunnel, the chinrest will be adjusted to keep the middle of the eyes at $7,5 \mathrm{~cm}$ above the road surface. The $5000 \mathrm{~K}$ classical white stimulus will be turned on and the observers will be asked if they can see the target, if so, the protocol will be then read to them from a written script so that every participant will have exactly the same instructions.

Observers will be instructed to look constantly at the target and to avoid looking directly at the light sources. They will be also instructed, for each pair, to state the stimulus which offers the best target visibility. After that, they will be maintained in the dark, eyes opened, for 3 minutes, then a pre-test will begin to familiarize the observer with the experiment, and finally the real test will start.

The experiment will be conducted with a LabVIEW program which presents the pairs in a random order. For each pair, the two stimuli will be presented during 5 seconds with 1 second of dark ( $\mathrm{COB}$ turned off) between them. Once the two spectra will have been seen by the observer, he will be able to ask the operator to repeat the pair if he wasn't able to decide which stimulus offered the best target visibility. The pair will be played as many times as necessary to get an answer from the observer. Then the next pair will be played and so on until the 36 different pairs have been seen by the participant. The total duration of the experiment is expected to be between 40 minutes and 50 minutes, less than an hour which should not tire the observers.

Around 40 participants will be recruited for the experiment. Most of them will likely be between 20 and 25 years old.

\section{Conclusion}

The objective of this study is to investigate the effect of Spectral Power Distribution (SPD) on visibility in road tunnels. To do so, a 1:20 scale-model, representative of a $100 \mathrm{~m}$ length tunnel, has been created. It is lit by 2 rows of 12 LED COB (Chips on Board LZ7 04M100 from LED Engin). These COBs include 7 different chips (red, green, blue, $6500 \mathrm{~K}$ white, amber, cyan and violet) which are individually controlled to create a wide range of spectra.

The psychophysical experiment will be conducted during the second half of May 2019. Three spectra representative of light sources for tunnels will be tested: HPS, $3000 \mathrm{~K}$ white LED and $5000 \mathrm{~K}$ white LEDs. Three additional spectra, metameric of the other three and providing twice as much melanopic excitation, will be tested to study the influence of ipRGCs on visibility. The luminance level on the road will be close to $4 \mathrm{~cd} . \mathrm{m}^{-2}$. The procedure used for the experiment will be a pairwise comparison. It has been selected because it is a very simple and understandable method, and because it will give us information about the potential biases of the experiment and about the consistency of the answers of observers.

The scale model built for this study offers many other possibilities:

- The surfaces (road, walls and ceiling) are modifiable, so that many different spectral reflection factors could be tested in possible future studies;

- The COB mounted on the tunnel can provide a multitude of different spectra which could be used for further experiments;

- Other luminance levels could also be used inside the tunnel to investigate the specific case of very long tunnels.

Although the scale model is adaptable, it is not appropriate for the specific study of glare in road tunnels. 
The final conclusions of the study regarding the impact of the spectrum of light on visibility in road tunnels should be available in the second semester of 2019.

\section{References}

BROWN T.M., TSUJIMURA S.I., ALLEN A.E., WYNNE J., BEDFORD R., VICKERY G., VUGLER A., LUCAS R.J. 2012. Melanopsin-Based Brightness Discrimination in Mice and Humans. Current Biology, 22, 1134-1141. (DOI: 10.1016/j.cub.2012.04.039).

BULLOUGH J.D., REA M.S. 2000. Simulated driving performance and peripheral detection at mesopic and low photopic light levels. Lighting Res. Technol., 32, 194-198. (DOI: 10.1177/096032710003200403)

CEN 2006. FD CEN/CR 14380. Lighting applications - Tunnel lighting. AFNOR.

CETU 2000. Dossier pilote des tunnels - éclairage. Lyon: SPECIFIQUE J.L.P.

CIE 2004. CIE 88:2004. Guide for the Lighting of Road Tunnels and Underpasses.

CIE 2010. CIE 191:2010. Recommended System for Mesopic Photometry Based on Visual Performance. Vienna: CIE.

CURCIO C.A., SLOAN K.R., KALINA R.E., HENDRICKSON A.E. 1990. Human Photoreceptor Topography. The Journal of Comparative Neurology, 292, 497-523. (DOI: 10.1002/cne.902920402).

ELOHOLMA M., HALONEN L. 2005. Performance based model for mesopic photometry. Report from the Mesopic Optimisation of Visual Efficiency (MOVE) project.

ESQUIVA G., LAX P., PÉREZ-SANTONJA J.J., GARCIA-FERNÁNDEZ J.M., CUENCA N. 2017. Loss of Melanopsin-Expressing Ganglion Cell Subtypes and Dendritic Degeneration in the Aging Human Retina. Front. Aging Neurosci., 9. (DOI: 10.3389/fnagi.2017.00079).

ESTEVEZ O., SPEKREIJSE H. 1982. The "Silent Substitution" Method in Visual Research. Vision Res., 22, 681-691. (DOI: 10.1016/0042-6989(82)90104-3).

GAMLIN P.D.R., MC DOUGAL D.H., POKORNY J., SMITH V.C., YAU K-W., DACEY D.M. 2007. Human and macaque pupil responses driven by melanopsin-containing retinal ganglion cells. Vision Res., 47, 946-954. (DOI: 10.1016/j.visres.2006.12.015).

GÓRCZEWSKA M., MROCZKOWSKA S., SKRZYPCZAK P. 2013. Light color influence on obstacle recognition in road lighting. Computer Applications in Electrical Engineering.

HE S.Y., TÄHKÄMO L., MAKSIMAINEN M., LIANG B., PAN G.B., HALONEN L. 2017, Effects of transient adaptation on drivers' visual performance in road tunnel lighting. Tunnelling and Underground Space Technology, 70, 42-54. (DOI: 10.1016/j.tust.2017.07.008).

MC DOUGAL D.H., GAMLIN P.D.R. 2010. The influence of intrinsically-photosensitive retinal ganglion cells on the spectral sensitivity and response dynamics of the human pupillary light reflex. Vision Res., 50, 72-87. (DOI: 10.1016/j.visres.2009.10.012).

REA M.S., BULLOUGH J.D., FREYSSINIER-NOVA J.P., BIERMAN A. 2004. A proposed unified system of photometry. Lighting Res. Technol., 36, 85-111. (DOI: 10.1191/1365782804li114oa).

YANG Y., BAO Z., ZHU C., WANG L. 2011. Study on the Mesopic Vision Theory Used in Road Tunnel Lighting Measurement. Third International Conference on Measuring Technology and Mechatronics Automation. (DOI: 10.1109/ICMTMA.2011.711).

ZAIDI F.H., HULL J.T., PEIRSON S.N., WULFF K., AESCHBACH D., GOOLEY J.J., BRAINARD G. C., GREGORY-EVANS K., RIZZO J.F., CZEISLER C.A., FOSTER R.G., MOSELEY M.J., LOCKLEY S.W. 2007. Short-Wavelength Light Sensitivity of Circadian, Pupillary, and Visual Awareness in Humans Lacking an Outer Retina. Current Biology, 17, 2122-2128. (DOI: 10.1016/j.cub.2007.11.034). 
ZELE A.J., ADHIKARI P., FEIGL B., CAO D. 2018a. Cone and melanopsin contributions to human brightness estimation. Journal of the Optical Society of America, 35, 19-25. (DOI: 10.1364/JOSAA.35.000B19).

ZELE A.J., FEIGL B., ADHIKARI P., MAYNARD M.L., CAO D. 2018b. Melanopsin photoreception contributes to human visual detection, temporal and colour processing. Scientific Reports, 8, Article number 3842. (DOI: 10.1038/s41598-018-22197-w). 